\title{
Climatogenic Dynamics of Solifluction in the Permafrost Zone of Central Siberia
}

\author{
Viacheslav I. Kharuk ${ }^{\mathrm{a}, \mathrm{b}}$, \\ Alexander S. Shushpanov and Sergey T. Im ${ }^{\mathrm{a}, \mathrm{b}, \mathrm{c}}$ \\ ${ }^{a}$ V.N. Sukachev Institute of Forest SB RAS \\ 50/28 Academgorodok, Krasnoyarsk, 660036, Russia \\ ${ }^{b}$ Siberian Federal University \\ 79 Svobodny, Krasnoyarsk, 660041, Russia \\ 'Siberian State Aerospace University M.F. Reshetnev \\ pr. Them. newspaper «Krasnoyarsk worker», Krasnoyarsk, 660014, Russia
}

Received 16.03.2015, received in revised form 30.03.2015, accepted 26.04.2015

Landsliding dynamics during recent decades within larch-dominant permafrost zone of Mid Siberia was analyzed. Studies were based on high and medium resolution data (QuickBird, WorldView, Landsat) and gravimetric measurements (GRACE). The landsliding occurrence increased since the year 2006. Landsliding were located on the southward slopes only, and its number exponentially increased with slope steepness increase. The upper limit of the landslides corresponded to tree line. Landslides occurrence correlated with August precipitation $\left(R^{2}=0.6\right)$ and drought index (SPEI: $R^{2}=0.49$ ), and with June -July-August gravimetric data (equivalent of water thickness anomalies, EWTA: $\left.R^{2}=0.47-0.49\right)$. SPEI and EWTA are correlated $\left(R^{2}=0.38\right)$. The significant increase of temporal divergence between maximal and minimal values of EWTA was observed.

Keywords: solifluction, permafrost in Siberia, larch forests, landsliding.

DOI: 10.17516/1999-494X-2015-8-6-744-754.

(c) Siberian Federal University. All rights reserved

* Corresponding author E-mail address: stim@ksc.krasn.ru 


\title{
Климатогенная динамика солифлюкции в мерзлотной зоне Средней Сибири
}

\author{
В.И. Харук ${ }^{\mathrm{a}, \tilde{0}}$, А.С. Шушпанов ${ }^{\mathrm{a}}$, С.Т. Им ${ }^{\mathrm{a}, \tilde{,}, \mathrm{s}}$ \\ ${ }^{a}$ Институт леса им. В.Н. Сукачева СО РАН \\ Россия, 660036, Красноярск, Академгородок, 50/28 \\ ${ }^{6}$ Сибирский федеральньий университет \\ Россия, 660041, Красноярск, пр. Свободный, 79 \\ ${ }^{8}$ Сибирский государственный \\ аэрокосмический университет им. М.Ф. Решетнева
}

Россия, 660014, Красноярск, пр. им. газетьл «Красноярский рабочий»

В лиственничниках мерзлотной зоны Средней Сибири исследована динамика оползней в начале ХХІ столетия. Использовались материалы дистанционного зондирования высокого и среднего пространственных разрешений (QuickBird, WorldView, Landsat), a также данные гравиметрической съемки (спутник GRACE). Установлено значительное возрастание числа оползней после 2006 г. Оползни локализованы только на склонах южной и юго-западной экспозиции; их число экспоненциильно возрастает с возрастанием крутизны склона. Высотный предел формирования оползней совпадает с верхней границей леса. Частота появления оползней коррелирует с осадками за август $\left(R^{2}=0.6\right)$ и индексом засухи $\left(R^{2}=0.49\right)$, а также с аномалиями водной массы в почвогрунтах за июнь-август (EWTA: $R^{2}=0.47$ -0.49). Значимая корреляция наблюдается между индексом сухости SPEI и EWTA $\left(R^{2}=0.38\right)$. Установлена значительная временная дивергенция минимальных максимальных значений EWTA.

Ключевые слова: солифлюкция, мерзлотная зона Сибири, лиственничники, оползни.

\section{Введение}

Солифлюкция - широко распространенное явление в бореальной зоне Евразии и Северной Америки [1-4], представляет собой процесс движения вниз по склону насыщенных водой почвогрунтов в пластичном состоянии по водонепроницаемому, обычно мерзлотному слою. Как и другие процессы, инициированные циклами замораживания-оттаивания, количество оползней возрастает при повышении водной массы в почве [2]. Ожидается, что в мерзлотной зоне с ростом количества осадков частота оползней будет увеличиваться [5].

Возрастание температуры мерзлотных почв в Сибири на $0.3-2{ }^{\circ} \mathrm{C}$ за последние десятилетия может привести к увеличению количества оползней, включая воздействие на инфраструктуру нефтегазовой промышленности $[6,7]$.

Солифлюкционные процессы в зоне вечной мерзлоты наблюдаются на обширных и удаленных территориях, что обусловило применение дистанционного зондирования и ГИСтехнологий в их исследованиях [8-11]. Традиционно применение спутниковой съемки основано на обнаружении изменений вегетационных индексов (например EVI, NDVI), детектировании открытых грунтов и лож оползней $[10,11]$. Новые перспективы открываются с запуском в 2002 г. спутника GRACE (Gravity Recovery and Climate Experiment), позволяющего измерять аномалии гравитационного поля Земли, обусловленные, в частности, изменениями водной массы в Арктике, Антарктике, а также в зонах вечной мерзлоты Сибири и Аляски [12-19]. 
Цель данной работы: 1) оценка воздействия наблюдаемых изменений климата (температура воздуха, количество осадков и индекс засушливости) на частоту оползней в зоне многолетнемерзлых почвогрунтов Средней Сибири; 2) определение пространственного распределения оползней (зависимость от азимута, высоты над уровнем моря, крутизны склона); 3) оценка применимости гравиметрической съёмки GRACE для анализа солифлюкционных процессов.

\section{Исследуемая территория}

Исследуемый регион расположен в северной части Средней Сибири и включает правобережную часть водосборного бассейна р. Кочечум с водосборами рек Тембенчимэ и Эмбенчимэ (общая площадь 62000 км²; рис. 1, 2). Территория расположена в зоне вечной мерзлоты и покрыта густой речной сетью. Перепад высот составляет от 100 до 1100 м над у.м.

Сезонная глубина оттаивания мерзлоты варьируется от 0.1 до 1 м. Леса сформированы лиственницей (Larix gmelinii Rupr.) и березой (Betula pendula Roth). Средняя сомкнутость древостоев составляет 0.2; средняя высота, диаметр на высоте груди и возраст 8.5 м, 12.5 см и 250 лет соответственно. Подлесок представлен кустарником (Betula nana, Salix sp, Ribes sp, Rosa sp., Juniperus sp, Vaccinium sp), живой напочвенный покров - лишайником и мхами.

\section{Климат}

Климат резко континентальный с холодной продолжительной зимой и коротким жарким летом (рис. 3). Летние температуры воздуха достигают $39{ }^{\circ} \mathrm{C}$.

С начала 1980-х гг. наблюдается положительный тренд температур (рис. 3а). С начала 1990-х гг. происходит рост количества осадков в августе и снижение годового количества осадков (рис. 3b), а также возрастание августовского индекса сухости SPEI (Standardized Precipitation-Evapotranspiration Index) (рис. 3c). Данные климатических показателей (среднемесячная температура воздуха, количество осадков и SPEI) получены из интернет-ресурсов [20,

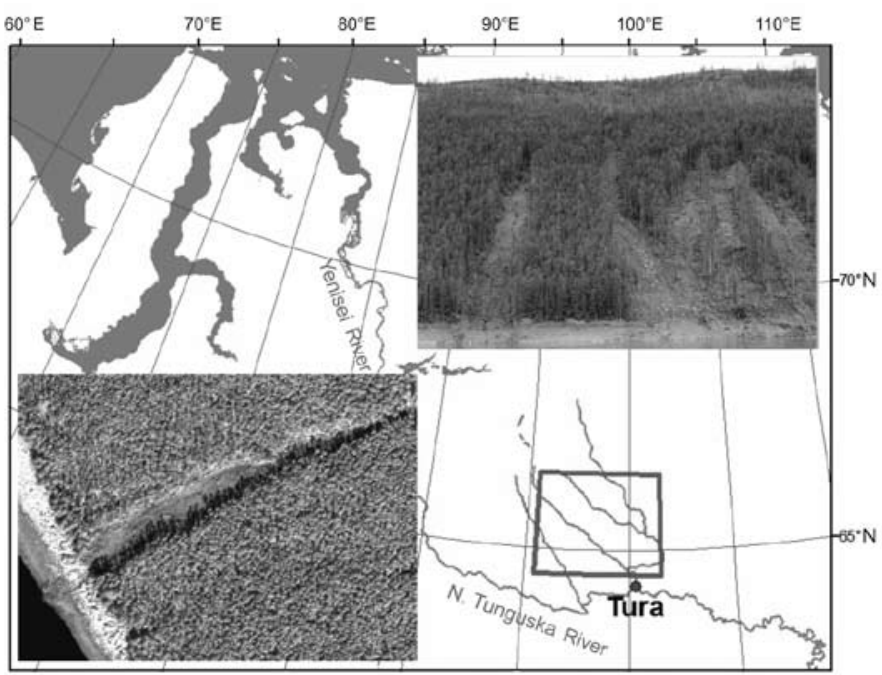

Рис. 1. Регион исследования выделен квадратом. Верхняя и нижняя вставки: наземный и спутниковый снимки оползней 


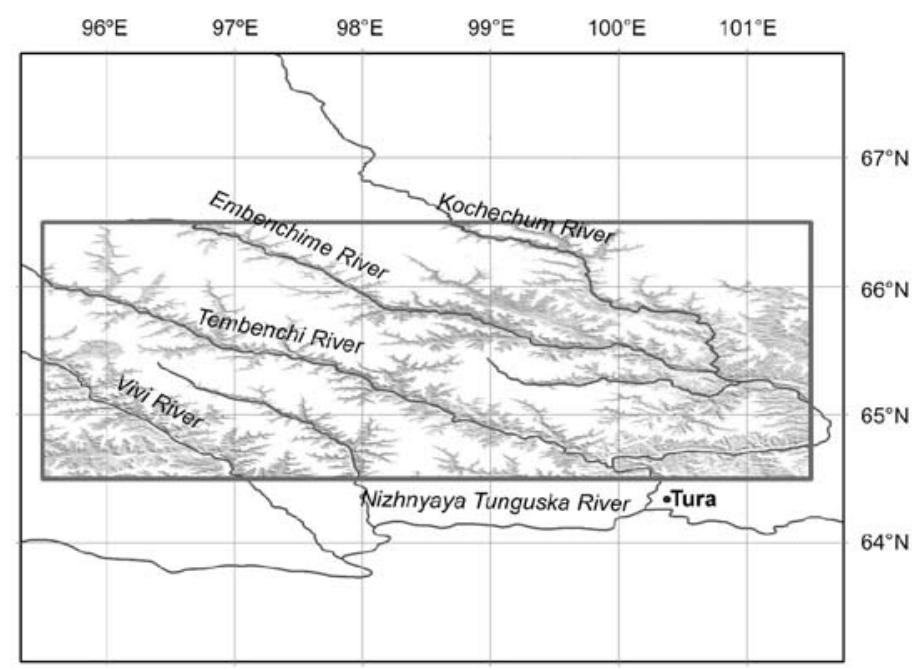

Рис. 2. Исследуемый регион (выделен прямоугольником). Контуры внутри прямоугольника: покрытие снимками сверхвысокого разрешения. Серый цвет: зона потенциальных оползней
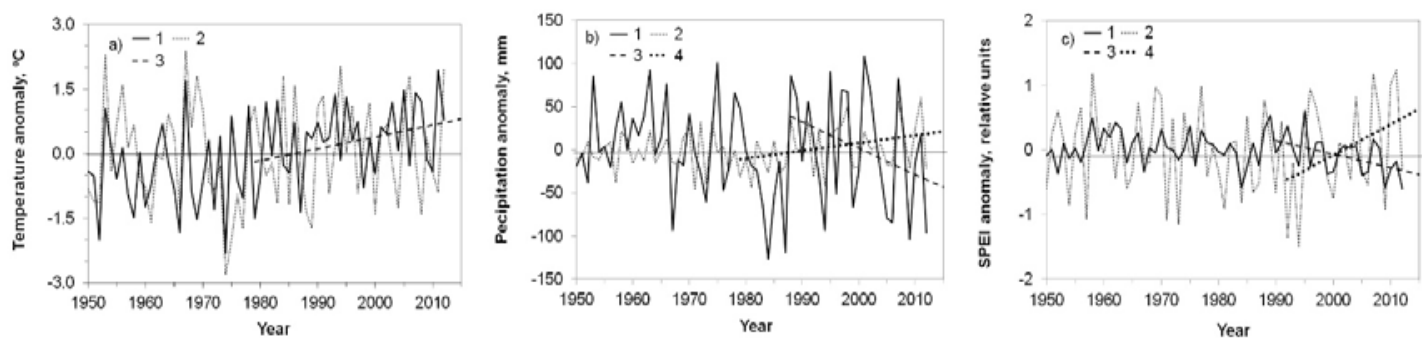

Рис. 3. Отклонение от средних значений (а) температуры (1 - годовая, 2 - июнь); (b) осадки (1- годовые, 2 - август); (c) SPEI (1 - годовой, 2 -август); 3, 4 - тренды

$21]$ и усреднены для ячеек $0.5^{\circ} \times 0.5^{\circ}\left(\sim 33 \times 56\right.$ км$\left.^{2}\right)$. Индекс SPEI позволяет оценивать степень засушливости, интенсивность и продолжительность засухи [22]. Для расчета SPEI используется помесячная разность $\left(D_{i}\right)$ между осадками $\left(P_{i}\right)$ и потенциальной эвапотранспирацией $\left(P E T_{i}\right)$ за период $i: D_{i}=P_{i}-P E T_{i}$.

\section{Материалы и методы}

\section{Спутниковые данные}

Для анализа использовали данные со спутников Landsat-7 (пространственное разрешение панхроматического канала 15 м), WorldView-1,-2 и QuickBird-2 (пиксель 0.5...0.6 м) и гравиметрические измерения GRACE. Временные ряды снимков Landsat, WorldView и QuickBird применяли для детектирования оползней. Данные GRACE использовали для оценки влажности почвы.

Снимки Landsat получены с интернет-ресурса USGS GloVis [23] (всего 50 шт., облачность $<10$ \%) за период с 1989 по 2012 г. Съемка сверхвысокого разрешения (всего 110 шт., летний пе- 
риод) охватывает период с 2004 по 2012 г. Общая площадь одной сцены сверхвысокого разреше-

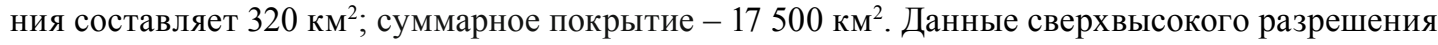
позволяют достоверно дешифрировать оползни (рис. 1). Однако их датировка была осложнена отсутствием снимков сверхвысокого разрешения за период с 2005 по 2008 г. С целью уточнения датировки была использована съемка Landsat (не менее трех сцен для каждого года).

Данные GRACE за период с 2003 по 2014 г. получены с сайта NASA [24] Пространственное разрешение GRACE составляет $1^{\circ} \times 1^{\circ}\left(\sim 112 \times 44\right.$ км² на широте $\left.66^{\circ}\right)$. К исходным данным применен фильтр Гаусса (300 км) и учтен эффект послеледникового поднятия земной коры. Применены восстанавливающие масштабирующие коэффициенты [25]. Данные GRACE позволяют измерять аномалии водного эквивалента массы (EWTA); единица измерения - см. EWTA представляет изменения наземных и подземных водных масс. При условии постоянства наземных водных масс EWTA показывает аномалии водных масс в почвогрунтах. В исследовании применены годовые и летние минимальные и максимальные значения EWTA. Точность измерений EWTA составляет 10-30 мм/месяц [26, 27]. Данные обрабатывались в программных пакетах Erdas Imagine [28] и ESRI ArcGIS [29].

\section{ГИС-анализ}

Распределение оползней по элементам рельефа (высота, азимут, крутизна склона) анализировалось с использованием цифровой модели рельефа (ЦМР) ASTER GDEM [30]. Горизонтальная точность ЦМР \pm 15 м; вертикальная точность \pm 6 м. ЦМР была разделена на высотные срезы с шагом 50 м. Верхний предел распределения оползней по высоте принят за 600 м над у.м. Из ЦМР рассчитаны ГИС-слои азимутальных направлений и крутизны склонов. Азимуты склонов были разделены на 8 групп с шагом 22,5 (северный, северо-восточный и т.д.). Минимальное значение крутизны склона принято за $10^{\circ}$, поскольку количество оползней на более пологих склонах было пренебрежимо мало. Полученные слои были объединены в многослойное изображение, в котором каждый пиксель содержал указанные характеристики рельефа.

Для учета неравномерного распределения элементов рельефа на исследуемой территории применена нормализация. Нормализованная площадь оползня (с заданными азимутом, крутизной склона и высотой н.у.м.) выражалась как отношение абсолютной площади оползня к общей площади элементов рельефа с аналогичными параметрами:

$$
K_{n}=\left(A_{c(i) f} / A_{c(i) I}\right)
$$

где $\mathrm{K}_{\mathrm{n}}$ - коэффициент нормализации; $c(i)$ - $i$-я категория элементов рельефа $c$; $\mathrm{A}_{c(i) f}$ - площадь данного класса элементов рельефа внутри $i$-й категории топографического признака $c$ на нарушенной территории; $\mathrm{A}_{c(i) I}$ - площадь $i$-й категории топографического признака $c$ внутри анализируемой территории.

\section{Результатьл}

За изучаемый период (2000-2012 гг.) произошло 145 оползней. Из них 31 оползень не удалось датировать с точностью до года; они были исключены из рассмотрения и в дальнейшем анализировали только оставшиеся 114 оползней.

$$
-748-
$$




\section{Оползни и орография}

Временная динамика и пространственное распределение оползней по элементам рельефа представлены на рис. 4, 5.

Число оползней экспоненциально возрастает с увеличением крутизны склона (рис. 4a). Все оползни локализуются на склонах южной и юго-западной экспозиций (рис. 4b). Количество оползней значительно возросло в последнюю декаду (рис. 5). Начинаются оползни преимущественно на высотах 200-300 м над у.м. (с максимумом до 650 м над у.м.). С ростом высоты над у.м. их количество сокращается в геометрической прогрессии. Протяжённость большинства оползней соответствует интервалу 75-225 м. Наблюдается корреляционная зависимость длины оползня от крутизны склона $\left(\mathrm{R}^{2}=0.13, \mathrm{p}<0.05\right)$. На основе данных по пространственному распределению оползней оценена потенциально опасная для развития солифлюкционных процессов территория ( 16 000 км², или $25 \%$ от общей территории; рис. 2).
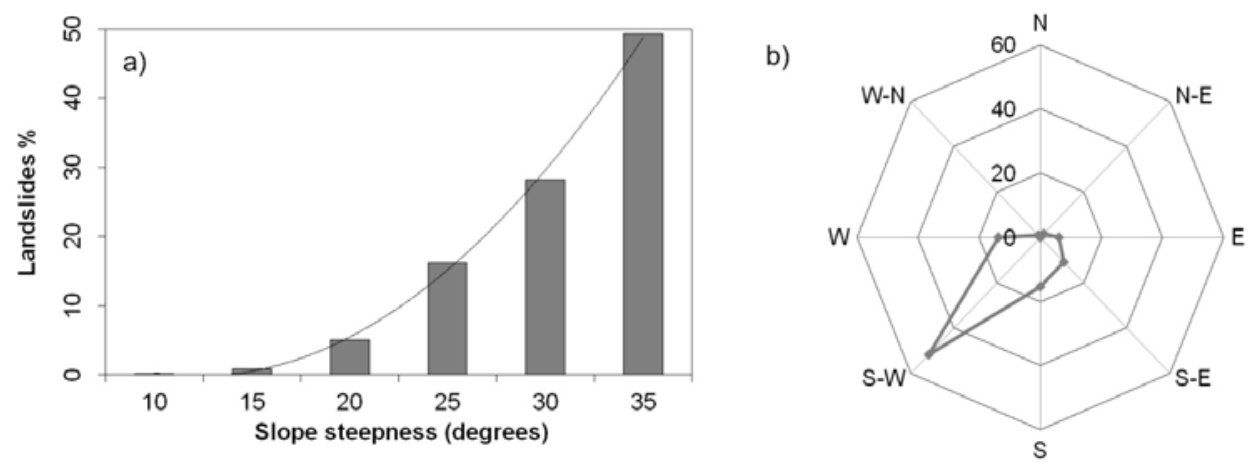

Рис. 4. Распределение оползней: $\mathrm{a}$ - по крутизне склона и $\mathrm{b}$ - по азимутам

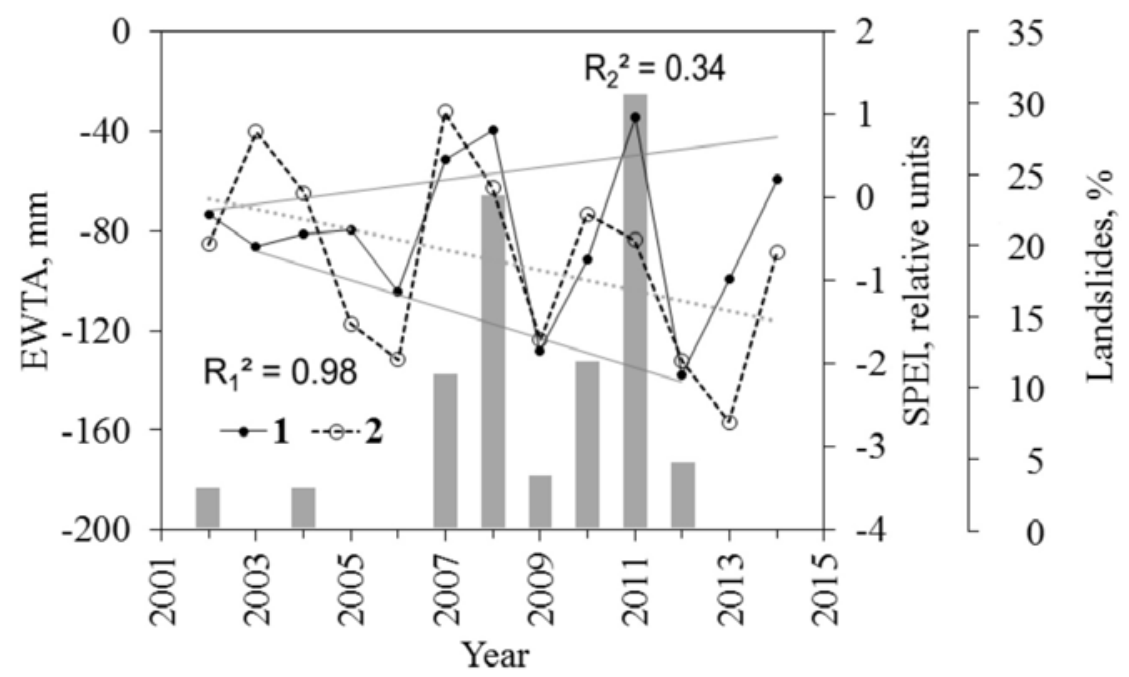

Рис. 5. Временные ряды 1) EWTA и 2) SPEI за август. Для EWTA показаны линейные тренды локальных минимумов $\left(\mathrm{R}_{1}^{2}\right)$ и максимумов $\left(\mathrm{R}_{2}^{2}\right)(\mathrm{p}<0.05)$. Столбцы: количество оползней (условные единицы) 


\section{Оползни и гравиметрические данные}

Количество оползней положительно коррелирует с аномалиями эквивалента водной массы (EWTA) за летние месяцы $\left(\mathrm{R}^{2}=0.47-0.49, \mathrm{p}<0.05\right.$; рис. $\left.6 \mathrm{~b}\right)$. Временная динамика данных EWTA и ее связь с количеством оползней представлены на рис. 5.

Индекс SPEI положительно коррелирует с EWTA, что указывает на тесную связь атмосферной засухи с аномалиями воды в почвогрунтах (рис. 5). Периоды максимумов влажности почвы совпадают с периодами максимумов числа оползней. Наблюдается достоверное увеличение расхождений между минимальными и максимальными значениями EWTA за период измерений (с 2002 по 2014 г.; рис. 5). Другими словами, происходит увеличение экстремальных максимумов и снижение экстремальных минимумов аномалий грунтовых вод.

\section{Оползни и климатические тренды}

Годовая динамика количества оползней коррелирует с величиной августовских осадков и SPEI (рис. 6a, c). Корреляция с летними температурами статистически незначима.

\section{Обсуждение}

\section{Оползни и рельеф территории}

Пространственная структура оползней неоднородна относительно азимута: все оползни локализованы на склонах южной и юго-западной экспозиции; ни один оползень не обнаружен на склонах северной экспозиции. Длина оползней варьируется в широком диапазоне: от коротких ( $\leq 50$ м) до протяжённых (>400 м). Вероятность образования оползня связана с крутизной склона: количество оползней экспоненциально увеличивается с возрастанием крутизны склона (рис. 4a). Максимальная высота «стартовой» точки оползней примерно совпадает с верхней границей леса (около 650 м над у.м.). Наличие древесной растительности имеет важное значение для активации оползней, поскольку (1) деревья представляют одну из компонент массы оползня и (2) корни деревьев, проникая глубже среднегодовой глубины оттаивания мерзлоты, в определённой мере препятствуют образованию оползня. Известно, что корни лиственницы частично остаются в замороженном горизонте почв даже летом [31]. Это происходит потому, что (1) в аномально теплые годы корни проникают в более глубокие горизонты почвы и (2) зоны корневого обитания сокращаются начиная с момента появления дерева. Последнее вызвано ро-
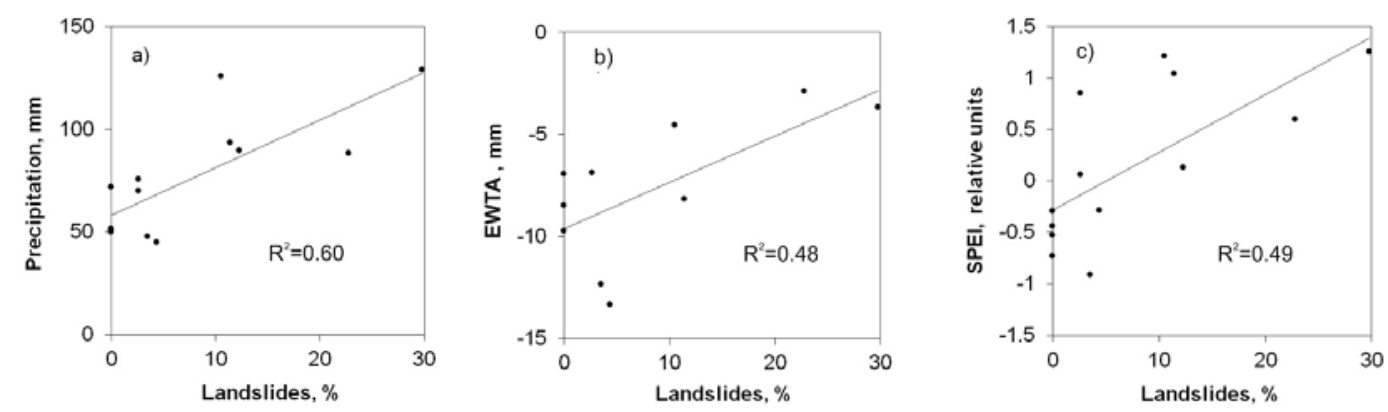

Рис. 6. Зависимость между количеством оползней и (а) осадками в августе, (b) EWTA, (c) индексом сухости SPEI 
стом напочвенного покрова в виде мхов и лишайников, действующих в качестве теплоизолятоpa [32]. В аномально тёплые годы наблюдается оттаивание почвогрунтов выше среднегодовых показателей, что приводит к потере сцепления корней с глубьлежащими слоями почвогрунтов. Таким образом, освобождение связи корней с мерзлотным слоем и возрастание содержания влаги в почве приводят к формированию оползня, к скольжению почвогрунтовых масс по слою вечной мерзлоты.

\section{Оползни и изменение климата}

Количество зарегистрированных оползней значимо связано с количеством осадков в августе, а также с величиной SPEI (рис. 5, 6). Вместе с тем не наблюдается значимой корреляции между количеством оползней и температурой воздуха. Накопление дождевых осадков в оттаявшем горизонте приводит к увеличению гравитационной движущей силы, увеличивая вероятность оползня. Кроме того, осадки увеличивают оттаивание вечной мерзлоты вследствие значительно большей (по сравнению с воздухом) теплоемкости воды. Данный результат согласуется с более ранними исследованиями об увеличении интенсивности солифлюкции после выпадения осадков [33] и подтверждает гипотезу об интенсификации солифлюкционных процессов с увеличением количества осадков [5]. Примечательно, что возрастание августовских осадков происходит на фоне снижения суммы летних осадков (рис. 3b). Связь между количеством оползней и SPEI аналогична таковой с осадками: чем меньше величина атмосферной засухи, тем выше количество оползней (рис. 6c).

\section{Оползни и аномалии водной массы}

Основными движущими силами для образования оползня служат глубина оттаивания и способность почв поглощать осадки. Количество оползней коррелирует с аномалиями водной массы в почвогрунтах в июне-июле-августе (рис. 6б). Последнее зависит от количества осадков и глубины оттаивания вечной мерзлоты. Оттаявшая вечная мерзлота обладает более высокой потенциальной емкостью для поглощения воды, потому что (1) плотность воды превышает плотность льда на 10 \% и (2) существуют свободные ото льда полости внутри вечной мерзлоты, которые после оттаивания становятся потенциальными резервуарами для осадков. Полученные данные GRACE свидетельствуют об увеличении в начале XXI в. экстремально высоких и низких значений аномалий водной массы в почвогрунтах и связанных с ними оползней (рис. 5). Поскольку по климатическим сценариям в Арктике к концу XXI в. произойдёт повышение температуры воздуха на 7 ... $11{ }^{\circ} \mathrm{C}[34,35]$, следует ожидать значительного увеличения глубины оттаивания мерзлотных грунтов, что приведёт наряду с общим изменением водного баланса к резкому возрастанию солифлюкционных процессов.

\section{Постоползневое восстановление растительности}

Открытое ложе оползня представляет собой начальный этап для последующего возобновления растительности. Эта проблема рассматривалась лишь в единичных исследованиях [31]. Сформированные оползнями свободные от растительности площади можно считать плацдармами для вторжения в зону доминирования лиственничников менее холодостойких. В настоящее время имеются свидетельства о миграции кедра (Pinus sibirica) и ели (Picea obovata) в зоне 
доминирования лиственницы [36]. Однако в целом постоползневая динамика растительности слабо изучена и требует дальнейших исследований.

\section{Заключение}

В лиственничниках мерзлотой зоны Средней Сибири наблюдается возрастание числа оползней в начале XXI столетия. Локализация оползней тесно связана с орографией территории: оползни наблюдаются исключительно на склонах южной и юго-западной экспозиции. Число оползней экспоненциально возрастает с возрастанием крутизны склона. Высотный предел их формирования совпадает с верхней границей леса. Частота возникновения оползней зависит от осадков $\left(\mathrm{R}^{2}=0.6\right)$, индекса сухости $\left(\mathrm{R}^{2}=0.49\right)$, а также от аномалий водной массы в почвогрунтах в июне-августе $\left(\mathrm{R}^{2}=0.47-0.49\right)$.

\section{Работа выполнена при поддержке Российского научного фонда, проект № 14-24-00112.}

\section{Список литературы}

[1] Горшков С.П., Ванденберг Дж., Алексеев Б.А. и др. Климат, мерзлота и ландшафты Среднеенисейского региона. М.: Наука, 2003. С. 81.

[2] Jones A., Stolbovoy V., Tarnocai C. et. al. Soil Atlas of the Northern Circumpolar Region. European Commission, Office for Official Publications of the European Communities (Luxembourg), 2010. $142 \mathrm{p}$.

[3] Wang B., Li H., Paudel B. (2009) Movement behavior of thawflows in permafrost soil. Geohazard. Available at http://www.landslides.ggl.ulaval.ca

[4] Wieczorek E.L., Gerald F., Geist R., Motyka J., Matthias J. (2007) Hazard assessment of the Tidal Inlet landslideand potential subsequent tsunami, Glacier Bay National Park, Alaska. Landslides Volume 4 Issue 3, 205-215.

[5] Montrasio L., Valentino R. (2008) A model for triggering mechanisms of shallow landslides. Natural Hazards and Earth System Sciences 8, 1149-1159.

[6] Romanovsky V.E., Drozdov D.S., Oberman N.G. et. al. (2010). Thermal state of permafrost in Russia. Permafrost Periglacial Process 21, 136-155.

[7] Anisimov O.A., Reneva S.A. (2011) C.A. Carbon balance in the permafrost zone of Russia and the global climate: current status and forecast based on modeling. Polar cryosphere land and water, $320 \mathrm{c}$.

[8] Huscroft C.A., Lipovsky P.S., Bond J.D. (2003) Permafrost and landslide activity: Case studies from southwestern Yukon Territory. Yukon exploration and geology, 107-119.

[9] Lyle R.R., Hutchinson D.J. and Preston Y. (2004) Landslide processes in discontinuous permafrost, Little Salmon Lake (NTS 105L/1 and 2), south-central Yukon. Yukon exploration and geology, 193-204

[10] Chau K.T., Sze Y.L., Fung M.K., Wong W.Y., Fong E.L., Chan L.C.P. (2004) Landslide hazard analysis for Hong Kong using landslide inventory and GIS. Computers \& Geosciences 30, 429-443.

[11] Booth A.M., Roering J.J., Perron J.T. (2009) Automated landslide mapping using spectral analysis and high-resolution topographic data: Puget Sound lowlands, Washington, and Portland Hills, Oregon. Geomorphology 109, 132-147. 
[12] Chen J.L., Wilson C.R., Blankenship D.D., Tapley B.D. (2006) Antarctic mass rates from GRACE. Geophysical research letters, vol. 33. L11502, doi:10.1029/2006GL026369.

[13] Gardner A.S., Moholdt G., Wouters B., Wolken G.J., Burgess D.O., Sharp M.J., Cogley J.G., Braun C., Labine C. (2011) Sharply increased mass loss from glaciers and ice caps in the Canadian Arctic Archipelago. Nature 473, 357-360, doi:10.1038/nature10089.

[14] Barletta V. R., Sorensen L. S., Forsberg R. (2013) Scatter of mass changes estimates at basin scale for Greenland and Antarctica. The Cryosphere 7, 1411-1432, doi:10.5194/tc-7-14112013.

[15] Groh A., Ewert H., Rosenau R., Fagiolini E., Gruber C., Floricioiu D., Abdel Jaber W., Linow S., Flechtner F., Eineder M., Dierking W. (2014) Mass, Volume and Velocity of the Antarctic Ice Sheet: Present-Day Changes and Error Effects. Surveys in Geophysics, doi: 10.1007/s10712-0149286-y.

[16] Steffen H., Muller J., Peterseim N. (2012). Mass Variations in the Siberian Permafrost Region from GRACE. Geodesy for Planet Earth, International Association of Geodesy Symposia, 136. pp. 597-603.

[17] Muskett R.R., Romanovsky V.E. (2011b) Energy and mass changes of the Eurasian permafrost regions by multi-satellite and in-situ measurements. Natural Science Vol.3, No.10, 827-836.

[18] Muskett R.R., Romanovsky V.E. (2011a) Article Alaskan Permafrost Groundwater Storage Changes Derived from GRACE and Ground Measurements. Remote Sensing 3, 378-397. doi:10.3390/ rs3020378

[19] Velicogna I., Tong J., Zhang T., and Kimball J. S. (2012) Increasing subsurface water storage in discontinuous permafrost areas of the Lena River basin, Eurasia, detected from GRACE. Geophysical research letters 39, L09403, doi:10.1029/2012GL051623, 2012

[20] British Atmospheric Data Centre. Available at http://badc.nerc.ac.uk.

[21] CRU TS3.1. KNMI Climate Explorer. Available at http://climexp.knmi.nl

[22] Vicente-Serrano S.M., Beguería S., López-Moreno J.I. (2010) A Multiscalar Drought Index Sensitive to Global Warming. The Standardized Precipitation Evapotranspiration Index. Journal Climate 23, 1696-1718.

[23] USGS GloVis. Available at http://glovis.usgs.gov

[24] GRACE Tellus (Gravity Recovery and Climate Experiment). Available at http://grace.jpl. nasa.gov

[25] Landerer F.W., Swenson S.C. (2012) Accuracy of scaled GRACE terrestrial water storage estimates. Water resources research, vol. 48, W04531, doi:10.1029/2011WR011453, 2012

[26] Riegger J, Tourian M, Devaraju B, Sneeuw N (2012) Analysis of grace uncertainties by hydrological and hydro-meteorological observations. $J$ Geodyn 59,16-27. doi:10.1016/j. jog.2012.02.001

[27] Long D, Longuevergne L, Scanlon B.R. (2014) Uncertainty in evapotranspiration from land surface modeling, remote sensing, and GRACE satellites. Water Resour Research 50(2),1131-1151. doi:10.1002/ 2013WR014581

[28] Erdas Imagine software. Available at http://geospatial.intergraph.com

[29] ESRI ArcGIS software. Available at http://www.esri.com

[30] ASTER GLOBAL DEM. Available at http://earthexplorer.usgs.gov/ 
[31] Abaimov A.P., Zyryanova O. A., Prokushkin S. G. (2002) Long-Term Investigation of Larch Forests in Cryolithic Zone of Siberia: Brief History, Recent Results and Possible Changes under Global Warming. Eurasian Journal of Forest Research 5, 95.

[32] Kharuk V.I., Dvinskaya M.L., Im S.T., Ranson K. J. (2011) Wildfires in northern Siberian larch dominated communities. Environmental Research Letters 6. doi:10.1088/1748-9326/6/4/045208 .

[33] Титов Э.Э. (1976) Основные черты современного коллювиального морфогенеза в горах Северо-Востока СССР. Геоморфология, 2. 11-25.

[34] Sillmann J., Kharin V.V., Zwiers F.W., Zhang X., Bronaugh D. (2013) Climate extremes indices in the CMIP5 multimodel ensemble: Part 2. Future climate projections. Journal of Geophysical Research: Atmospheres 118, 2473-2493.

[35] Vaks A., Gutareva O.S., Breitenbach S.F.M., Avirmed E., Mason A.J., Thomas A.L., Osinzev A.V., Kononov A.M., Henderson G.M. (2013) Speleothems Reveal 500,000-Year History of Siberian Permafrost. Science 340, 183-186.

[36] Kharuk V.I., Dvinskaya M.L., Im S.T., Ranson K. J. (2005) Expansion of Evergreen Conifers to the Larch-Dominated Zone and Climatic Trends. Russian Journal of Ecology 36, 164-170. 